\title{
Divisão de Administração Pública das Nações Unidas: Resumo Histórico $\left(^{*}\right)$
}

\author{
Louis E. Hosch \\ Chefe da Seção do Pessoal e de Treinamento \\ da Divisão para a Administração Pública, \\ do Departamento de Assuntos Econômicos \\ e Sociais \\ Tradução de AlBert Wolbert
}

$\mathrm{O}$

programa de assistência técnica das Nações Unidas no dominio da administração pública provém, de certo modo, do primeiro artigo da Carta das Nações Unidas. A redação clara das seções 3 e 4 do artigo $1^{\circ}$ certamente fornece uma estrutura geral de referência dentro da qual funciona o programa:

"Art. 19 São as seguintes as finalidades das Nações Unidas: $(\ldots)$

3. Conquistar a cooperação internacional para a solução de problemas de caráter econômico, social, cultural ou filantrópico, promover e incentivar o respeito pelos direitos humanos e pelas liberdades fundamentais a todos, sem distinção de raça, sexo, lingua e religião; e

4. Constituir-se num centro de harmonização dos atos das nações para atingir êsses objetivos comuns."

\section{ORIGENS}

A idéia existente dentro das Nações Unidas de ajudar os governos a melhorar as práticas administrativas é tão antiga quanto o próprio programa de assistência técnica. Há pouco mais de uma década, a Assembléia Geral das Nações Unidas, em sua ter * ceira sessão de dezembro de 1948, aprovou pela primeira vez um programa de assistência técnica subordinado ao orçamento

(*) "Revue Internationale des Sciences Administratives", vol. XXX, 
ordinário. A resolıção 200 da Assembléia Geral, que dispõe inter alia

"Considerando que:

a) A promoção de condições de progresso econômico $e$ social e de desenvolvimento é um dos principais objetivos da Carta das Nações Unidas,

b) A falta de pessoal especializado e a ausência de organização técnica são alguns dos fatôres que impedem o desenvolvi* mento econômico das regiões subdesenvolvidas, (...)

Decide consignar os fundos necessários que possibilitem ao Secretário-Geral executar as seguintes funções (...)

a) Proporcionar à organização equipes internacionais compostas de especialistas, fornecidos pelas Nações Unidas ou através destas, $(\ldots)$ com a finalidade de assessorarem aquêles go-

b) Proporcionar facilidades para o treinamento, no exterior, de especialistas de países subdesenvolvidos, mediante a concessão de bôlsas de estudos (...)

c) Proporcionar treinamento aos técnicos locais dentro dos próprios paises subdesenvolvidos ( ...)"

A resolução, neste ponto, determinou ao Secretário-Geral tomar sob sua responsabilidade a execução dessas funções; conceder assistência técnica aos governos que a solicitassem, para êles ou através dêles; satisfazer as necessidades do govêrno em questão e na forma em que cada país o desejasse; e conceder assistência de alta qualidade e competência técnica.

É significativo que, no mesmo dia, naquela sessão da Assembléia Geral, tenha sido adotada uma resolução (a resolução GA 246 | III | de 4 de dezembro de 1948), que marcou o reconhecimento inicial da necessidade de treinamento em administração pública. Eis a resolução:

"Reconhece a necessidade de criação de facilidades internacionais que proporcionem treinamento administrativo adequado a um número cada vez maior de candidatos de comprovada capacidade, recrutados numa ampla base geográfica, mas principalmente dos países com maior necessidade de acesso aos princípios, normas e métodos da moderna administração,

Resolve que:

18) Um Centro Internacional de Treinamento em das Nações 
2\%) O Secretário-Geral apresentará relatórios minuciosos sôbre êsse Centro ao Conselho Econômico e Social;

3:) O Secretário-Geral deverá incluir em sua previsão orçamentária para o ano fiscal de 1950 um programa de implementação dos objetivos da presente resolução."

Assim, a preocupação com a administração pública iniciou-se com o conceito de um centro internacional de treinamento em administração pública. Contudo, a idéia original da criação de um centro internacional tornou-se, na época, impraticável.

\section{OS PRIMEIROS ANOS}

Durante 1949, um "programa" para proporcionar treinamento em administração pública foi esboçado no relatório do SecretárioGeral na $9^{\text {a }}$ sessão do Conselho Econômico e Social, e um orçamento de US\$ 149,500 para 1950 foi aprovado pela Assembléia Geral em sua 4a sessão. O programa foi aprovado pela Assem. bléia Geral em 1949 e compreendia:

a) Seminários sôbre problemas administrativos, destinados a altos funcionários;

b) Bôlsas de estudos em administração pública para estu. dante e graduados;

c) Assistência de especialistas aos governos para o desen. volvimento de facilidades de treinamento em administração pública;

d) Assessoramento e assistência aos Estados Membros na promoção de troca bilateral de funcionários civis; e

e) Incentivo e assistência financeira ao Instituto Internacional de Ciências Administrativas (IIAS), para troca de informações sôbre assuntos de administração pública.

Em 1949, o reconhecimento da necessidade de assistência no campo da administração pública, ,mediante a introdução de facilidades internacionais, afastou-se da idéia do treinamento circunscrito a um programa que levou as atividades para dentro dos paises que necessitassem dessa assistência. Essa mudança foi em sua maior parte iniciada pela resolução 253 (IX) da Assembléia em 1949, que solicitou ao Secretário-Geral coordenar as finalidades iniciais com as do programa mais amplo e mais geral da assistência técnica.

\section{SURGEM FUNÇÕES MAIS AMPLAS}

Em 1950, e nos poucos anos seguintes, a associação do programa de administração pública com o programa mais amplo de 
assistência técnica à administração resultou numa extensão do programa incluindo outras funções além do treinamento. Conforme dissemos acima, novas funções foram acrescentadas. Foi assim possivel ampliar o programa constante das decisões de 1948 e 1949 para a "assistência técnica ao desenvolvimiento econômico de países subdesenvolvidos", como definido pela Assembléia Geral e pelo Conselho Econômico e Social (na resolução GA 200 de 1948 e resolução ECOSOC 22 A (IX)' de 14 de agôsto de 1949).

Em 1950, o Conselho Econômico e Social deu maior reco. nhecimento ao programa para a administração pública por meio de uma resolução (292, XI), que recomendava fôssem aquelas atividades adicionais no campo da administração pública consideradas sob o programa expandido de assistência técnica. Abriu, assim, o caminho para um programa mais amplo, que foi confirmado e prosseguido pela Assembléia Geral em 1951, por meio da resolução 518 (VI).

Em fins de 1951, a Divisão de Administração Pública toi estabelecida dentro da Administração de Assistência Técnica. Um exame de cada uma das seis atribuições da nova Divisão mostra como o conceito do programa total de 1949 tinha evoluido já em fins de 1951. Nessa época, as atribuições da Divisão de Administração Pública eram como aparecem abaixo descritas. Observa-se, para cada uma delas, a mudança significativa da anterior especificação de funções.

A. Aparecimento da função de assessoria e assistência
(especialistas)

A primeira das seis novas funções foi:

“a) desenvolver e administrar um programa de assistência técnica em administração pública, incluindo seminários, conferências e grupos de trabalho sôbre as. suntos de importância para a melhoria da administração pública, e de assessoría e assistência aos governos para o aperfeiçoamento da administração pública e o estabelecimento ou reforma de sistemas de treinamento e instituições regionais e nacionais em regiões subdesen.

Uma comparação desta função com "um programa de şminários sôbre problemas administrativos para altos funcionários", como foi autorizado em 1949, revela uma sensivel expansão das finalidades e a introdução de novas técnicas. De grande impor* tância, foi a introdução de "assessoria e assistência aos governos na melhoria da administração pública." 
A primeira nova função consistiu na atribuição dada à Divisão de "desenvolver e administrar um programa" que incluisse "o estabelecimento ou a reforma de sistemas de treinamento e de instituições regionais e nacionais em paises subdesenvolvidos." Esta ampliação foi significativa por duas razões:

a) proporcionou uma estrutura de referência para o estabelecimento de sistemas de treinamento nacionais e regionais, estendendo assim a assistência do treinamento ao âmbito nacional e regional, e

b) usou a expressão "instituições em países subdesenvolvidos" - expressão que deu grande latitude, nos poucos anos seguintes, à extensão do programa em assuntos de organização governamental e práticas administrativas.

\section{B. A nova atribuição de coletar informações}

A segunda nova função da Divisão foi assim definida:

“b) coletar informações técnicas no setor da administração pública com a finalidade de selecionar e desenvolver métodos efetivos para assistência técnica nessa esfera e aumentar os conhecimentos relativos às condições reais e possiveis necessidades de tal assistência nas áreas subdesenvolvidas."

Essa descrição assinala o aparecimento da primeira referência às funções de "coletar informações", "desenvolver métodos efetivos" e "aumentar os conhecimentos relativos às condições reais", como técnicas especificas de assistência técnica na administração pública.

Esta nova função marcou o início de um programa que poderia ser desenvolvido nos anos seguintes com o emprêgo de vários métodos de ensino, investigação e pesquisa, em apoio às operações de assistência técnica. Tornou possivel o uso de estudos preparatórios e a compilação sistemática de certos tipos de informação sôbre uma área regional ou problemática, a fim de ajudar diferentes países na solução de vários tipos de problemas.

\section{Expansão da função da troca de informações}

A terceira função, expansão de uma antiga idéia, assim se definiu:

“c)' estimular e facilitar a coleta e troca de informações em colaboração com o Instituto Internacional de Ciências Administrativas e outras instituições apropriadas." 
O mais significativo, no caso, foi a "colaboração com o Instituto Internacional de Ciências Administrativas e outras instituições apropriadas", mais uma subordinação ao incentivo e assis. tência financeira apenas ao instituto por troca de informações sôbre assuntos de administração pública.

A expansão desta função possibilitou à Divisão utilizar outras organizações internacionais não-governamentais (tal como a União Internacional de Autoridades Municipais e outras) para a coleta e intercâmbio de informações.

\section{Análise de problema: uma nova função}

De nôvo nasceu uma nova função para o programa que deveria, nos últimos anos, ser empreendida em escala maior, e assim definida:

“d) analisar problemas de administração pública com particular referência a áreas subdesenvolvidas, e estudar uma relação com o desenvolvimento econômico e social."

Era uma nova atividade para a Divisão, similar a funções de outras áreas especificas do programa de assistência técnica.

A introdução desta responsabilidade obrigou a Divisão a examinar seu programa total, tendo em vista as várias esferas de especificação em administração pública além do treinamento, e estudar de maneira sistemática várias especializações, tais como organização e métodos, administrações de governos municipais, orçamentos, contabilidade e auditoria, etc. Esta mudança em parte possibilitou que a Divisão atendesse a consultas governamentais sôbre assistência técnica numa maior variedade de assuntos.

\section{E. Formação de outras responsabilidades especificas} segue:

A quinta das seis novas atribuições foi definida como se

“e) auxiliar no recrutamento de especialistas e na seleção, esclarecimento e colocação de estudantes e graduados no campo da administração pública."

Essa medida transformou a Divisão em sócio do Diepartamento do Pessoal das Nações Unidas e responsável por estas tante papel de

tora técnica de especialistas e suas tarefas. e a localização de fonteşão em si exigia a coleta de materiais 
dos governos e suas práticas habituais de administração. À medida que se expandiu o número de especialistas servindo em missões de administração pública, esta tarefa se tornou considerável, acabando por exigir o estabelecimento de uma unidade de referência na Divisão.

\section{F. Avaliação dos resultados de projetos}

A última das seis atribuições foi assim definida:

“f) avaliar os resultados da assistência técnica em administração pública."

Esta atividade proporcionou a oportunidade de se reverem os relatórios apresentados pelos especialistas, a fim de avaliar o andamento de um projeto e determinar se o "método" empregado pelo especialista foi suficientemente completo, se um programa praticável de trabalho foi lestabelecido, e se todos os recursos disponiveis estavam sendo completamente utilizados. Nos relatórios finais, os resultados puderam ser avaliados pelas declarações originais das finalidades.

Mais importante do que o processo de avaliação de relatórios isolados, esta nova função possibilitou a avaliação de diferentes tipos de projetos no mesmo campo de especialização. Tornou também possivel a avaliação das diferentes técnicas empregadas pelos especialistas de diferentes procedências, trabalhando no mesmo campo de especialização. Como conseqüência destas atividades, os funcionários da Divisão desenvolveram habilitações especiais para avaliação de vários métodos e técnicas usados na solução de problemas administrativos e adquiriram conhecimento sôbre o desempenho de trabalho dos especialistas, indicando alguns que poderiam ser usados com vantagem em outras atribuiçớes.

Com estas novas funções, a Divisão apareceu em $1952 \mathrm{com}$ operações de assistência técnica em sua sede como uma unidade impar e, isso, por duas razões:

a) Tornou-se cada vez mais reconhecida como unidade específica, cujas responsabilidades e interêsses penetravam em quase tôdas as atividades específicas de assistência técnica, por causa da importância central da administração pública em atingir os fins e apoiar todos os aspectos dos empreendimentos econômicos e sociais do govêrno.

b) Foi a única unidade remanescente na sede da Administração de Assistência Técnica que conservou tanto as funções operacionais como as específicas. 


\section{EVOLUÇÃO DO PROGRAMA DEPOIS DE 1950}

Nos estágios iniciais do desenvolvimento do programa foi dada prioridade aos seminários, estudos e centros de treinamento. Em fins de 1950, foi organizado na sede um seminário sôbre problemas de pessoal. No seminário de 1951, um centro de treinamento foi organizado em São Salvador, seguido por um seminário sôbre órgão de assessoria e serviços auxiliares, no Rio de Janeiro, entre novembro de 1951 e março de 1952. No comêço de 1952, um folheto sôbre padrões e técnicas de administração pública $(\mathrm{ST} / \mathrm{TAA} / \mathrm{M} / 1)$ foi publicado como resultado de uma conferência realizada na sede pelos especialistas no assunto.

A partir dêsses esforços específicos, o programa começou a desenvolver-se em certas áreas, o que, visto em retrospecto. pode ser considerado como a exploração dos vários usos que poderiam ter as funções da Divisão. Em outubro de 1953, a Assembléia Geral observou na resolução 723 (VIII) que o programa de atividades da Divisão, atendendo às suas primeiras resoluções 246 (III) de 4.de dezembro de 1946, e 518 (VI) de 12 de janeiro de 1947, já não era mais adequado e que as atividades da Divisão formavam parte integrante do programa mais amplo de assistência aos governos, incluindo outros aspectos além do treinamento. Em conseqüência, a resolução autorizava ao SecretárioGeral continuar incluindo nas previsões orçamentárias os fundos necessários à execução de um programa mais amplo e financiar atividades com funções disponíveis do Programa Expandido de Assistência Técnica.

A Comissão de Assistência Técnica declarou oficialmente (em E/2566) que nos primeiros anos do programa houve certa relutância por parte dos governos em solicitar assistência técnica no campo da administração pública. "Quer essa relutância tenha nascido de uma suposta alergia de instituições administrativas e politicas contra influências externas, de uma subestimação da importância do aperfeiçoamento administrativo para os programas de desenvolvimento econômico-social, quer de uma resistência das fôrças tradicionais, a necessidade de assistência técnica tem sido cada vez mais reconhecida." Em dezembro de 1956, o reconhecimento cada vez maior da importância da administração públicã para a assistência técnica resultou, entre outras considerações, na adoção por parte da Assembléia Geral, da resolução 1.024 (XI). que endossava as recomendações do Secretário-Geral para que fôsse intensificada a atividade no campo da administração pública. Ao mesmo tempo, a Assembléia Geral aumentou a importância de fundos anuais disponiveis do Programa Regular de $\$ 145,000$ para $\$ 300,000$.

As seis funções básicas acima descritas foram empregadas de vários modos pela Divisão e seus associados. Embora não seja 
possível precisar a evolução de cada função, o desenvolvimento do programa em uma década pode ser descrito sucintamente, observando-se tendências significativas em cada uma das três seguintes áreas principais das atividades da Divisão:
A. Atividades de treinamento
B. Uso de especialistas.
C. Investigações e Pesquisa.

Òbviamente, estas três áreas principais de atividades não se excluem mùtuamente; técnicas de investigação e de treinamento foram empregadas por especialistas e èstes, por seu lado, foram aproveitados em programas de treinamento ou empreendimentos de investigação.

Há vários aspectos significativos dos esforços da Divisão na década passada, no campo do treinamento em administração pública. Observaram-se contínuos esforços por parte da maioria dos especialistas em treinar funcionários do govêrno com os quais trabalhavam. Partilhar com outros conhecimentos e novas técnicas e demonstrar novioś e mais eficientes métodos de levar avanté operações rotineiras do govêrno é quase invariàvelmente uma forma de treinamento. Crescendo o número de especialistas e o número de paises servidos, expandiu-se também êsse tipo de treinamento. Mas outro treinamento mais formal estava também em desenvolvimento: 0 uso de bôlsas de estudos e a utilização de centros ou institutos nacionais ou regionais de treinamento em administração pública.

O treinamento, de certo modo, é um aspecto da administração de pessoal no serviço público, no qual se empenhou grande número de técnicos servindo à Divisão. Num sentido mais amplo, o treinamento incluía não só o que estava sendo feito para fortalecer as funções de treinamento dos sistemas de serviço civil nos países em desenvolvimento, mas também incluia esforços suplementares, principalmente:

a) a concessão de bôlsas de estudos para treinamento no exterior $\mathrm{e}$

b) o estabelecimento ou fortalecimento de institutos nacionais ou regionais de administração pública.

\section{A. Institutos e Escolas de Administração Pública}

\section{Centros Regionais}

O programa de treinamento da Divisão deu prioridade, inicialmente, aos institutos regionais ou escolas de administração pública. Já em 1951, El Salvador era a sede de um primeiro esfôrço no sentido de estabelecer um centro de treinamento, seguido pela 
criação, em março de 1952, de uma Escola regional de Administração Pública no Rio de Janeiro. $\left({ }^{\star}\right)$ As obras preparatórias para a criação do Instituto de Administração Pública da Turquia e Oriente Médio tiveram início em julho de 1952 e o Instituto foi estabelecido em 1953. Um mês depois, em abril de 1953, foram iniciados os trabalhos preparatórios para a criaçäo de uma Escola Superior de Administração Pública na América Central.

Assim, no espaço de um ano, de março de 1952 a abril de 1953, a Divisão concentrou seus esforços em três centros regionais de treinamento. Embora as finalidades gerais dos três centros fôssem semelhantes, cada qual tinha uma base de operação diferente. O Instituto da Turquia operava em conjunto com uma Universidade, a Escola Brasileira, como parte do programa nacional de uma fundação particular e a Escola da América Central era dirigida por uma comissão criada pelos Governos das Repúblicas Centro-Americanas, representadas por seus Ministros de Economia.

O treinamento nos centros do Brasil e da Turquia tinha por finalidade atender inicialmente estudantes do pais, embora suas instalações fôssem oferecidas a outros países. A Escola CentroAmericana, por outro lado, sempre manteve um programa para atender de um modo geral os países da América Central.

\section{Centros Nacionais de Treinamento}

O programa de treinamento em administração pública da Divisão, por meio da ajuda dos centros nacionais de treinamento, foi elevado ao plano nacional na Libia (originalmente destinado ao treinamento de contadores e mais tarde ampliado e transformado no Instituto de Administração Pública) e no Egito, onde um Instituto foi criado com a cooperação da Comissão do Serviço Civil Egípcio, para funcionários públicos. No Egito, o Instituto recebeu ajuda de uma fundação particular dos Estados Unidos, para iniciar treinamento destinado a pessoal de escritório e estenógrafos, como parte do diversificado programa do Instituto de treinamento profissional e técnico de funcionários públicos.

Na década 1950-1960, vinte e três institutos nacionais foram criados ou reforçados com a ajuda de fundos da assistência técnica das Nações Unidas. O ritmo de criação dos institutos foi relativamente constante, com exceção dos anos de maior atividade, 1954 e 1955.

\section{Bôlsas de Estudos Para Estudantes e Graduados}

A concessão de bôlsas de estudo para graduados tornou-se uma caracteristica cada vez mais importante do programa de $\left(^{\star}\right) \quad N . T$.
da Fundação Getúlio Vargala Brasileira de Administração Pública (E.B.A.P.), 
treinamento da Divisão no período de 1954-1963. Partindo de um modesto comêço de 38 bôlsas em 1954, o número subiu a um total de 249 em 1962, com perspectivas de cêrca de 275 para. fins de 1963.

$\mathrm{Na}$ última década, foram elaborados programas especiais com a ajuda de governos doadores e instituições de treinamento. $O$ treinamento nos vários campos especializados da administração pública foi usado em muitos países com a finalidade de proporcionar uma variedade de recursos destinada a atender determinadas necessidades, que iam desde cursos para atender a uma função específica, tal como arrecadação de impostos, até os de maior responsabilidade, como, por exemplo, o ensino da administração pública.

\section{B. Aproveitamento de Especialistas}

O programa de treinamento da Divisão assumiu padrões bastante definidos, inicialmente em instituições de treinamento regional, e mais tarde lem instituições näcionais de treinamento com finalidades especiais, por meio de bôlsas de estudo para graduados em instituições acadêmicas nacionais ou pela observação da prática de repartições bem estabelecidas. A medida que o número de bôlsas aumentava, também crescia o número de técnicos servindo a uma grande variedade de necessidades em paises em desenvolvimento, partindo de um modesto comêço de 11 técnicos em 1950, para 209 em 1962.

A Divisão prestou assistência aos governos por meio de órgãos regionais das Nações Unidas, formulando definições precisas das espécies de trabalhos que deviam ser entregues aos técnicos, ajudou na seleção, instruiu-os com informações antes de se apresentarem aos serviços, orientou-os sôbre os aspectos espe. cíficos do trabalho durante o curso de suas obrigações até à entrega de relatórios finais aos governos.

As tarefas externas dos técnicos variavam de acôrdo com as necessidades dos paises solicitantes. Não parece haver padrão discernivel que diferencie essas tarefas. No decorrer da década, alguns países precisaram de especialistas para assisti-los nos aspectos mais amplos da estrutura governamental e na distribuição de funções mais importantes do govêrno. Algumas vêzes, grupos de técnicos eram utilizados para atender tais necessidades. Para atender outros pedidos, alguns técnicos eram enviados para ajudar governos em problemas administrativos de um só ministério ou de um de seus departamentos. Vários governos solicitaram assistência para a solução de problemas administrativos em quase todos os setores dos serviços públicos e em todos os niveis do serviço civil, do mais alto pôsto aos mais baixos. 
Investigação e Pesquisa

No comêço da década de 1950 , com o aparecimento das funções mais amplas da Divisão, acima descritas, a Divisão iniciou esforços, numa escala limitada, com a finalidade de "coletar informações técnicas" e "aumentar os conhecimentos relativos às condições reais." Êstes primeiros esforços incluiam dois métodos:

a) $\mathrm{O}$ uso do Instituto Internacional de Ciências Administrativas, estimulado e assistido pela Divisão a tomar sob sua responsabilidade a coleta e publicação de informações sôbre práticas administrativas, e

b) O uso dos relatórios regulares, apresentados em número crescente pelos especialistas ou grupos de especialistas em tarefas externas.

Entre 1951 e 1954, o I.I.A.S. publicou 24 estudos no campo da administração pública, programados para serem publicados com a ajuda das Nações Unidas. Foram entregues a governosmembros e muitos dêles foram reimpressos e traduzidos para uso de seus funcionários: desde então, muitos foram reimpressos várias vêzes.

Em 1953, o Instituto Internacional de Ciências Administrativas, com modesta ajuda financeira dos recursos da Divisão de Administração Pública, começou a publicação de um periódico internacional "Progress in Public Administration". Mais tarde, em 1956, essa publicação foi assimilada a uma outra das Nações Unidas, transformando-se em publicação profissional sob o titulo "International Review of Administrative Sciences", que vinha sendo publicada em francês desde 1928 e que trazia artigos em inglês, francês e espanhol. Esta ajụda a um jornal já existente, com grande circulação nas edições francesa e inglêsa, garantiu à Divisão um meio regular de divulgar informações sôbre as atividades do programa de assistência técnica das Nações Unidas a um grupo seleto de cientistas politicos e a profissionais com tarefas externas. Este é um dos meios adotados para estimular interêsse entre os que faziam pesquisas sistemáticas e também de suscitar o interêsse entre muitos dos que poderiam fornecer dados autênticos aos investigadores. A Divisão pôde usar como elo entre si e muitas instituições ligadas à coleta de informação útil sôbre a corrente prática administrativa sua análise e avaliação.

Merecem menção especial os Seminários sôbre a Organização e Administração de Emprêsas Públicas realizados em Rangum em 1954 e em Nova Delhi em 1959. Os documentos básicos da conferência do Seminário de Rangum foram publicados pelas Nações Unidas com o título "Some Problems of the Organization and Administration of Public Enterprises in the Industrial Field", ao passo que a I.I.A.S. publicava "Public Enterprise", editado 
por A. H. HANSON, um estudo comparativo da emprêsa pública, baseado no Seminário e sua documentação. $\left({ }^{\star}\right)$

No ano seguinte, 1957, o emprêgo pela Divisão de orga nizações não-governamentais, tais como a I.I.A.S., estendeu-se à Associação Internacional de Ciência Politica e, mais tarde, à União Internacional de Administradores Municiais, em conexão com pesquisas sôbre problemas de descentralização, inclusive govêrno local. A pesquisa em administração local foi iniciada com um estudo de "Public Administration Aspects of Community Development Programmes" (United Nations Sales n 59.II.H.2). O estudo foi realizado pela Divisão em colaboração com as agências especializadas e o Bureau de Negócios Sociais das Nações Unidas. Seguiu-se a êle a publicação, preparada pela Divisão, de um relatório sôbre a Descentralização para o Desenvolvimento Nacional e Local, em parte baseado num estudo elaborado em seu nome pela Associação Internacional de Ciência Politica. Êste relatório tratava principalmente de problemas de descentralização de unidades regionais e administrações locais em zonas rurais. A pesquisa de desenvolvimento e descentralização das comunidades chamou a atenção para a importâneia de órgãos centrais, governamentais e não-governamentais, para prestarem serviços técnicos e financeiros às administrações locais. A União Internacional de Administradores Locais foi, então, solicitada a elaborar um estudo comparativo de "Central Services to Local Authorities", concluido em 1962 e atualmente usado como documentação básica experimental em seminários regionais sôbre o assunto na Ásia e América Latina. Vários dos estudos elaborados sôbre êsses países pela I.U.L.A. aparecem numa recente publicação das Nações Unidas, entitulada "Local Government in Selected Countries" (Sales n 63.II.H.1). Outras publicações no campo do govêrno local incluem "Public Administration Problems of New and Rapidly Growing Towns in Asia" (Sales n' 62.II.H.1), o relatório de um seminário das Nações Unidas-Unesco e "Administrative Problems of Rapid Urban Growth in the Arab States" (Sales $n^{\circ}$ 63.II.H.2).

A investigação sistemática e a pesquisa, contudo, prosseguiram lentamente; "nunca se cogitou no Secretariado, ou mesmo se julgou possível, tentar descobrir, pela pesquisa, um conjunto de remédios soberanos para tôdas as enfermidades administrativas. As atividades de pesquisa promovidas pelas Nações Unidas ou com a ajuda de organizações externas foram dirigidas para a coleta e estudo analítico de fatos e experiências num certo número de países diferentes, a fim de possibilitar, para informação e guia dos que procuram aumentar sua eficiência administrativa

(*) N. T. - A Fundação Getúlio Vargas lançou o ano passado, sob o título "Emprêsas Públicas", o livro de textos selecionados pelo Prof. Frank SHERWOOD, entre os quais muitos relativos à Conferência de Rangum. 
em países menos desenvolvidos, uma coleção de exemplos dos quais poderão selecionar alguns que possam ser, com mais propriedade, seguidos ou adaptados na solução de suas necessidades particulares."

As declarações acima resumidas da politica seguida pela Divisão em maio de 1960 (E/3.366, pág. 47), explica em parte o número relativamente pequeno de documentos que até então foram publicados pela Divisão ou publicados sob seu patrocinio. A despeito daquela política original, a Divisão mais tarde julgou necessário produzir mais estudos comparativos tais como o "Training in Public Administration in 1958" (Sales n' 58.II.H.1).

Em 1961, a Divisão publicou "A Handbook of Public Administration" (Sales $n^{\circ}$ 61.II.H.2) - "um estudo que procura enumerar e correlacionar os elementos constantes e fundamentais no progresso da administração pública e sugerir aos governos os campos mais valiosos da experiência em administração, em que possam tirar proveito do programa de assistência técnica". A publicação dêsse manual proporcionou em grande parte uma revisão da experiência de técnicos numa década e identificou importantes áreas de acôrdos sôbre problemas e soluções relacionados pelos técnicos que serviam à Divisão.

\section{O PROGRAMA OPEX}

O programa das Nações Unidas para a criação de pessoal operacional, executivo e administrativo (OPEX), foi de responsabilidade da Divisão de Administração Pública desde 1959, e a seguinte exposição conta a origem e o subseqüente desenvolvimento e execução do programa.

\section{GÊNESIS DO PROGRAMA}

O programa OPEX iniciou-se formalmente como extensão à assistência técnica no campo da administração pública, com a adoção da resolução 1.256 (XIII), na 13 $3^{a}$ sessão da Assembléia Geral, sancionando fundos para um ano "em modesta escala e em base experimental" para assistência aos Governos (..) e assegurar em bases temporárias os serviços de pessoal bem qualificado, capaz de executar funções de natureza operacional ou nos (...)"

É importante reconhecer, contudo, que a assistência técnica dada por esta forma aos Governos sofreu sanção implícita, se não explícita, desde o comêço das atividades de assistência técnica das Nações Unidas. Os "Princípios Guias" contidos no anexo 1 da Resolução ECOSOC 222 (XIX), regulando o programa expandido, reafirmam os "principios gerais" estabelecidos na ante- 
rior resolução 200 (III), cobrindo assistência técnica para o desenvolvimento econômico, e declaram, inter alia.

"Os tipos de serviços a serem prestados a cada pais serão decididos pelo Govêrno em questão."

e de nôvo que a assistência técnica será prestada

"tanto quanto possível na forma em que o pais o desejar $(\ldots)$ "

Contudo, durante a primeira década de assistência técnica pelas Nações Unidas e as agências especializadas, a assistência especializada, quando prestada, tomava a forma de assessoria especializada prestada por pessoal assessor, no emprêgo do tempo integral das Nações Unidas ou de uma ou outra das agências especializadas. As Nações Unidas, contudo, fizeram exceções, notadamente no caso da Bolivia, em seguida à Missão Keenleyside em 1950, e mais tarde na Indonésia, com relação ao Comitê de Planejamento Indonésio. Em ambos os países, as Nações Unidas facilitaram encontros de técnicos" que executavam "funçôes operacionais e executivas." As Nações Unidas subvencionaram seu emprêgo em postos dos Governos, depois de estabelecidos acôrdos com os governos interessados.

As Nações Unidas fizeram também exceções no emprêgo de técnicos especializados onde as circunstâncias tornavam impera\{ivo que os técnicos não só "assessorassem" mas também "executassem" certas funções. Num certo país foi feita concessão especial no acôrdo suplementar então em vigor, a fim de permitir ao assessor meteorológico exercer a função de "Diretor dos Serviços Meteorológicos." Novamente, no mesmo país, um assessor de estatística montou um Escritório Central de Estatística e assumiu as funções de facto de Diretor, o que mais tarde foi reconhecido pelas Nações Unidas por acôrdo escrito. A dificuldade, no entanto, estava em proteger as Nações Unidas dos resultados de atos executivos feitos por seus técnicos em tais circunstâncias. Embora o Govêrno tenha concordado em manter as Nações Unidas "não prejudicadas" por tais atos, esta decisão não foi considerada inteiramente satisfatória. A posição do meteorologista tornou-se crítica quando, a certa altura, não conseguiu que o govêrno fizesse instalações adequadas de previsão de tempo em um dos aeroportos, com o risco constante de acidentes sérios. Se tais acidentes houvessem ocorrido, como Diretor dos Serviços Meteorológicos o especialista das Nações Unidas teria de prestar declarações e, por mais que as Nações Unidas e seu especialista fôssem moralmente inocentes, seriam inevitàvelmente envolvidos no caso. Depois de vários anos, o Govêrno indicou seus próprios auxiliares nacionais para assumir a responsabilidade executiva em ambos êsses postos. 
O próprio programa OPEX, contudo, teve sua origem em idéias que o Secretário-Geral anterior apresentou pùblicamente em discurso proferido no Canadá em 1956, quando falou do valor que os Governos podem conferir ao estabelecimento de um "Serviço Internacional Administrativo." Previu o desenvolvimento de uma equipe de técnicos das Nações Unidas, cujos membros seriam recrutados pela Organização para sua colocação em postos do govêrno, em atendimento a solicitações dos Governos para tais serviços. As propostas foram consideradas pela ECOSOC durante 1958, mas quando foram apresentadas à Assembléia Geral durante a 13" Sessão, o plano para um "Serviço Internacional Administrativo" foi derrubado, devido a objeções a certas implicações do plano, feitas por certos Governos. Em seu lugar, a Assembléia Geral autorizou o dispêndio de \$250,000 durante 1959 para o programa "experimental" referido no parágrafo 1 (acima).

\section{DESENVOLVIMENTO POSTERIOR}

A Organização das Nações Unidas para a Educação, Ciência e Cultura acompanhou as Naçôes Unidas em 1960 ao estabelecer um programa, com seu próprio orçamento regular, para assistência operacional em seu campo de competência (Únesco PAS), enquanto, ao mesmo tempo, continuava sua colaboração com as Nações Unidas no Programa OPEX das Nações Unidas, destinado a ocupar postos-chave nos campos da Unesco que mantinham um alto elemento da administração pública. Medidas similitares foram tomadas pela Organização Mundial da Saúde em 1962, referentes à assistência operacional, com seus próprios recursos, de postos da Organização em Colaboração com as $\mathrm{Na}$ ções Unidas, no preenchimento de postos-chave sujeitos ao Pro-
grama OPEX das Nações Unidas.

Durante a 14a Sessão do Conselho Social e Econômico e na 17 Sessão posterior da Assembléia Geral, levantou-se a questão do aumento dos recursos financeiros disponiveis para ếsse tipo de assistência. Uma decisão foi deferida, até que a Comissão de Assistência Técnica tivesse examinado a questão e tivesse apresentado seu relatório ao Comitê de Assistência Técnica. O
TAB fêz propostas especificas ao TAC para uso da Conta Especial do Programa Expandido, a fim de atender solicitações de assistência operacional do govêrno feitas por tôdas as organizações participantes. O TAC apoiou essas propostas e o Conselho Social e Econômico posteriormente incorporou as na resolução 951 (XXXVI) da ECOSOC. Finalmente, a Assembléia apoiou as propostas da ECOSOC na $18^{\text {a Sessão, adotando a resolução } 1.946}$ (XVIII), mediante a qual os Fundos da EPTA poderiam ser usados experimentalmente nos anos de 1964 a 1966 e os resultadas renovados na $21^{\text {a }}$ sessão. 


\section{EXECUÇÃO DO PROGRAMA}

Como foi indicado no parágrafo 52 acima, o programa foi iniciado como resultado da adoção da resolução 1.256 (XIII) pela Assembléia Geral. O preâmbulo dessa resolução diz o seguinte:

"A Assembléia Geral, reconhecendo o importante papel da administração pública na implementação de programas de desenvolvimento social e econômico, e (...)

Observando, além disso, que certo número de governos têm expressado o desejo de obter assistência temporária das Nações Unidas ou por meio delas, com a finalidade de preencher postos executivos ou operacionais em seu mecanismo administrativo $(\ldots)$ "

\section{A resolução então anotou}

“com satisfação os resultados já obtidos no campo da administração pública $(\ldots)$

e deu autorização ao Secretário-Geral para usar a forma de assistência da OPEX como "suplemento a êsses programas (de administração pública) ( ...)"

Se bem que não houvesse nenhuma prescrição restrita no uso dos têrmos "administração pública" e que desde o início os postos fôssem alvo tanto da cadeia total de campos das Nações Unidas como das agências especializadas, havia, contudo, interêsse primordial das Nações Unidas nesse programa, como atividades no campo da administração pública.

Assim, a Divisão de Administração Pública sempre forneceu direção substantiva no desenvolvimento do programa, primeiro como divisão específica da Administração de Assistência Técnica, em seguida, resumidamente, como Escritório para a Administração Pública e, finalmente, desde o comêço de 1959, como divisão específica do Departamento de Negócios Econômicos e Sociais.

Além do mais, a necessidade de coordenar os pareceres de todos os ramos do Departamento, como também tôdas as opiniões das agências especializadas envolvidas, no tratamento da implementação das solicitações, ditou a decisão de concentrar-se, em 1960, como questão de conveniência administrativa, tanto o trabalho substantivo como operacional da OPEX dentro da Divisão para a Administração Pública. O Diretor da Divisão exerce ai um contrôle geral do programa, de conformidade com as condutas administrativas da Comissão de Operações de Assistência Técnica. Êsse Diretor fornece ao Secretário-Geral e ao Subsecretário para Assuntos Econômicos dados específicos sôbre o programa e exerce contrôle de suas operações, através de Agente de Assistência Técnica, 


\section{REORGANIZAÇÃO DA DIVISÃO}

Històricamente, a Divisão de Administração Pública foi ornizada internamente em bases geográficas, com a finalidade de servir a várias regiões maiores do mundo. Em 1961 e 1962, deu-se ênfase crescente à politica de descentralização das atividades econômicas e sociais das Nações Unidas e fortalecimento das comissões econômicas regionais. A Divisão de Administração Pública tratou de preservar o caráter regional de seu programa, adotando o sistema de descentralização e estabelecendo (resolução 723). sob seu Programa Regular de Assistência Técnica, um número de postos regionais para consulentes em administração pública, que servissem às comissões regionais.

Tendo em mente esta adaptação do padrão regional das atividades da Divisão, fêz-se uma adaptação simultânea na estrutura interna da Divisão e nas linhas funcionais. Mais tarde, em 1961, o núcleo da nova estrutura interna foi estabelecido pela criação de três seções e uma unidade, como segue:

a) Seção de Pessoal e Treinamento,

b) Seção do Govêrno Local,

c) Seção de Organização e Métodos,

d) Unidade da OPEX.

Esta reorganização, que entrou em plena operação no comêço de 1962, foi destinada a cumprir as seguintes finalidades:

$1^{\text {a }) ~ E n c a r e c e r ~ a ̀ ~ c a p a c i d a d e ~ d a ~ D i v i s a ̃ o ~ p r e s t a r ~ c o n t r i b u i c ̧ a ̃ o ~}$ qualitativa e profissional a seus campos de competência mais im-
portantes;

2.) Desenvolver o caráter específico da Divisão como unidade integral do Departamento de Negócios Sociais e Econô-
micos;

3a) Melhorar os serviços regionais e descentralizados dos países em desenvolvimento e dos novos paises, com a ajuda de consultantes regionais e especialistas regionais, e

4:) Possibilitar à Divisão lutar com mais eficiência contra O excesso de trabalho da OPEX e dos Programas de Assistência
Técnica Regular Expandida.

\section{PROGRAMA ATUAL E PROJETADO DA DIVISÃO}

Em fins de 1963, a Divisão estava comprometida com extenso programa de ajuda específica a mais de duzentos técnicos em administração pública e quase uma infinidade de projetos inter-regionais, envolvendo pesquisas, seminários regionais e interregionais e conferências. Muitos dos projetos inter-regionais eram continuação de pesquisas ou estudos comparativos iniciados nos 
anos anteriores; outros foram iniciados em 1963 e alguns dos projetos atuais foram programados para terem continuação até 1966 .

O seguinte trecho de programa de trabalho da Divisão, nos fins de 1963, mostra-nos a série de projetos envolvendo estudos e documentação planejados para 1964 e anos seguintes e ilustra o amplo campo de ação e a variada matéria do programa da $\mathrm{Di}$ visão:

a) Preparação de Manual sôbre Leis do Serviço Civil e Regras de Pessoal e Regulamentações para Paises em Desenvolvimento;

b) Preparação de Manual sôbre Administração de Pessoal no Serviço Público: Princípios básicos e práticas correntes;

c) Preparação de Guia para Programas de Treinamento Nacional e Institutos de Administração Pública;

d) Preparação de Guia para a formulação de uma Série de cursos básicos de Treinamento para serviços internos no campo da administração pública;

e) Principios de Métodos de Compra e Fornecimento Governamental;

f) Utilização de Processamento Mecanizado de Dados nas Operações Governamentais;

g) Relações Legais e Administrativas entre Emprêsas Públicas e Estatais,

h) Estudo Inter-regional dos Aspectos Administrativos e Organizacionais dos Serviços de Agricultura;

i) Serviços Administrativos a Grupos Nômades;

j) Estudos sôbre Agências de Organização e Métodos e seu funcionamento;

k) Estudos sôbre Aspectos Administrativos de Urbanização;

l) Seleção e consolidação de listas de referência em preparação de uma Bibliografia anotada no campo de Administração Pública;

m) Análise comparativa de Arranjos Administrativos para Crédito das Autoridades Locais.

Em têrmos estatísticos, o alcance e o crescimento do programa da Divisão de Administração Pública é mostrado no seguinte quadro, que inclui o número de técnicos servindo no campo, o número de bôlsas de estudos concedidas e os gastos anuais totais de 1954 a março de 1963 no Programa Regular (resolução n 723 (VIII), o Programa Expandido de Assistência Técnica, Fundos em Truste e Pessoal Executivo e Operacional sujeito à resolução 1.256 (XIII). 


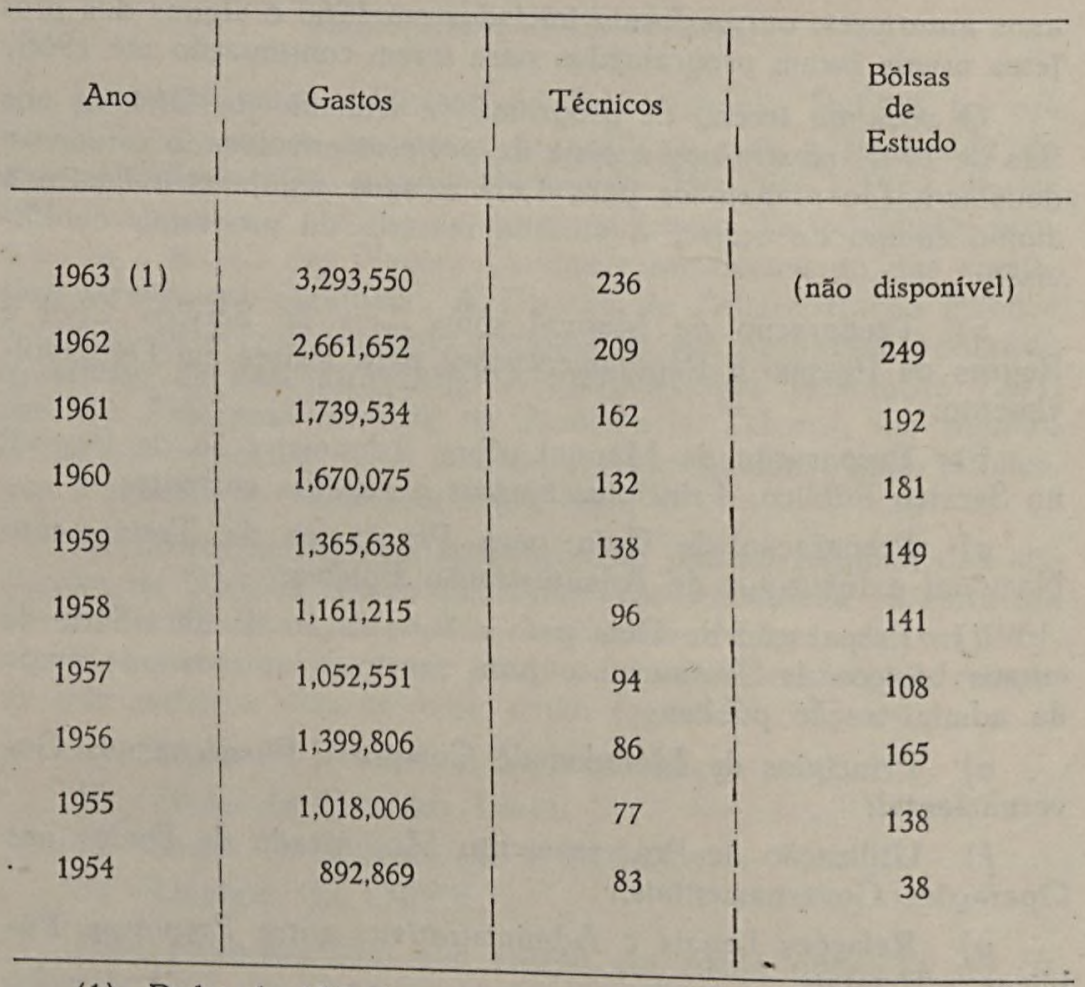

(1) Dados de 15-3-63, resoluções 723 e 1.256; e de 1-1-63, EPTA e Fundos-em-Truste.

Assim, o programa atual e em projeto da Divisão de Administração Pública estava no caminho certo na contribuição de sua modesta participação à mais ampla e maior tarefa da Década do Desenvolvimento das Nações Unidas. Reconhecendo que o desenvolvimento implica não sòmente nas necessidades materiais do homem mas também nas suas aspirações humanas mais elevadas, o programa no campo da administração pública assume seu papel de protetor da década, fortalecendo e ajudando no aperfeiçoamento das estruturas básicas e dos serviços essenciais dos governos em paises novos e em desenvolvimento. 